\title{
Rotavirus Infection among Diarrhoeal Children under 10 Years of Age Visiting a Children's Hospital in Kathmandu, Nepal
}

\author{
Rama Khadka ${ }^{*}$, Jeevan Bahadur Sherchand ${ }^{2}$, Shaila Basnyat ${ }^{3}$, Ranju Shrestha ${ }^{4}$, \\ Nabaraj Adhikari ${ }^{3}$ \\ ${ }^{1}$ Padmakanya Multiple Campus, Bagbazar, Kathmandu, Nepal \\ ${ }^{2}$ Tribhuvan University Institute of Medicine, Public Health Research Laboratory, Kathmandu, Nepal \\ ${ }^{3}$ Central Department of Microbiology, Tribhuvan University, Kritipur, Kathmandu \\ ${ }^{4}$ Kantipur College of Medical Science, Tribhuvan University, Sitapaila, Kathmandu \\ *Corresponding author: Rama Khadka; Padmakanya Multiple Campus, Bagbazar, Kathmandu, \\ Nepal; Email: khadkarama2072@gmail.com
}

\begin{abstract}
Objectives: The present study was conducted to assess the rate of rotavirus causes of diarrhoea among children under 10 years of age visiting a children's hospital in Kathmandu, Nepal.

Methods: This study was carried out from October 2010 to July 2011. During the study, a total of 1068 diarrheal stool samples were collected from inpatient and outpatient department of children less than 10 years of age attending Kanti Children's Hospital and processed in Public Health Research Laboratory, Tribhuvan University Teaching Hospital (TUTH). About $5 \mathrm{ml}$ of fresh diarrhoeal stool samples was collected and were transferred into vials which were preserved by adding buffer solution for detection of rotavirus. Samples for rotavirus antigen detection were detected by using Enzyme Immuno Assay. Data were entered into Microsoft excel and SPSS and analysis was done employing Chi-square test.
\end{abstract}

Results: Among 1068 total cases, 22.0\% (235/1068)children were infected with rotavirus which was found to be highest in inpatient $(26.2 \%)$ with severe case $(37.1 \%)$ then outpatients $(12.1 \%)$. Rotavirus were found to be highest in male children (22.9\%) under 2 years (23.8\%) of age group. Among all season, the rotavirus infection was highest in winter seasons $(29.6 \%)$ followed by spring season $(26.7 \%)$ and others. According to father occupation and mother education, the prevalence of rotavirus was found to be high in children with fathers having occupation labor $(27.8 \%)$ and found to be higher in children with illiterate mother (38.9\%).

Conclusion: The routine diagnosis of rotavirus in Nepal is not done. So it can be concluded that routine stool examination should include detection of Rotavirus antigen in diagnosis of acute pediatrics diarrhoeal illness which helps in manangement for diarrhoeal population.

Key words: Diarrhoea, Rotavirus, ELISA, Nepal

\section{INTRODUCTION}

Diarrhoea remains the second leading cause of death among children under five globally. Nearly one in five child deaths about 1.5 million each year is due to diarrhoea. Diarrhoea is a common symptom of gastrointestinal infections caused by a wide range of pathogens, including bacteria, viruses and protozoa (WHO, 2009).Cumulative data from epidemiological studies show that approximately 20-50 \% of diarrhoeal cases are attributable to known bacterial or parasitic pathogens, which suggests that viruses may be responsible for the remainder (Black et al. 2001).
Five million children under the age of 2 years die from diarrhoeal disease in developing countries each year, rotavirus infections account for about $20.0 \%$ of these deaths (Desselberger et al. 2006).Rotavirus infections occur worldwide. Globally, each year, 2 million children are hospitalized and 700,000 children die due to rotavirus diarrhea (Uchida et al. 2006). Rotavirus is estimated to cause about $40.0 \%$ of all hospital admissions due to diarrhoea among children under five years of age worldwide leading to some 100 million episodes of acute diarrhoea each year that result in 350,000 to 600,000 child deaths (WHO, 2009). 
Among three human Rotaviruses (A, B and C), group A Rotaviruses have been established as causing several diarrhoeal diseases in infants and young children worldwide (Estes 2001). By the age of five, nearly every child in the world has been infected with Rotavirus at least once (Velazquez et al. 1996). However, with each infection, immunity develops and subsequent infections are less severe. So adults are rarely affected (Bishop 1996).

Diarrhoeal disease occupied the second place among the top ten diseases in Nepal (NPR, 2007). It has been estimated that approximately $25 \%$ of child death are associated with diarrhoeal diseases, particularly acute diarrhea (Sherchand et al. 2011). Studies published on rotavirus infection from 1999 to 2007 showed rotavirus positivity rates ranged from $17.0-39.0 \%$ (median $31.8 \%$ ) in among all hospitalized children less than 5 years (Shariff et al. 2004; Sherchand et al. 2004; Uchida et al. 2006; Pun 2007; Sherchand et al. 2009; ).

In Nepal rotavirus is a leading cause of acute diarrhoea in children less than 5 years old, accounting for up to $38.0 \%$ of all diarrhoea cases (Black et al. 2001; Sherchand et al. 2009) however, the routine diagnosis of rotavirus is not done in Nepal. This study aims to explore the rate of Rotavirus infection among children's visiting the tertiary hospital of Nepal. This study will reveal the current status of Rotavirus infection in Nepal and helps in the managements of such population.

\section{MATERIALS AND METHODS}

This study was carried out from October 2010 to July 2011. During the study, a total of 1068 diarrheal stool sampleswere collected from inpatient (747) and outpatient (321) department of children less than 10 years of age attending Kanti Children's Hospital and processed in Public Health Research Laboratory, Tribhuvan University Teaching Hospital (TUTH). During the visit on Children's Hospital for collection of sample, questionnaires on different demographics were filled up. Verbal consent was obtained from patient parents. About $5 \mathrm{ml}$ of fresh diarrhoeal stool samples was collected from babie's diapers or clean bed pans or direct in possible cases with a clean plastic spatula in Clean, leak proof, screw capped plastic container. Samples were transported to the laboratory as soon aspossibleand subjected to macroscopic examination in which the direct visualization of each sample was done for the color, consistency and presence of mucus, blood. Then samples were transferred into vials which were preserved by adding buffer solution for detection ofrotavirus. Samples for Rotavirus antigen detection were detected by using an antigen detection test (ELISA kit of Premier Rotaclone; Meridian Bioscience, USA), according to the instructions of the manufacturer.

Data were entered into Microsoft excel and SPSS and analysis was done employing Chi-square test. The Chisquare test was performed with a significance level of< 0.05 for statistical analysis.

\section{RESULTS}

Out of total stool samples, $22.0 \%$ of children were found to be infected with rotavirus in which inpatient children showed the highest positive cases $(26.2 \%)$ than outpatient children which was $12.1 \%$.

Table 1: Distribution of Rotavirus among patients depending on hospital admission

\begin{tabular}{lcccc}
\hline \multirow{2}{*}{ Patient } & \multirow{2}{*}{ Total N (\%) } & Rotavirus & Negative & \multirow{2}{*}{ P-Value } \\
\cline { 3 - 4 } & & $\mathrm{N}(\%)$ & $\mathrm{N}(\%)$ & \\
\hline Inpatient(ORT) & $747(70.0)$ & $196(26.2)$ & $551(73.8)$ & \multirow{2}{*}{0.05} \\
Outpatient(OPD) & $321(30.0)$ & $39(12.1)$ & $282(87.8)$ & \\
\hline Total & $1068(100)$ & $\mathbf{2 3 5 ( 2 2 . 0 )}$ & $\mathbf{8 3 3 ( 7 8 . 1 )}$ & \\
\hline
\end{tabular}

The diarrheal children with different symptoms cases

which were $76.4 \%$ and $37.1 \%$ respectively. and severe cases showed higher rotavirus infection

Table 2: Distribution of Rotavirus according to clinical symptoms and clinical cases

\begin{tabular}{llll}
\hline Different clinical symptoms & Total Cases N (\%) & Rotavirus N (\%) & Negative N (\%) \\
\hline Yes & $816(76.4)$ & $199(24.4)$ & $617(75.6)$ \\
No & $252(23.6)$ & $36(14.3)$ & $216(85.7)$ \\
\hline Total & $1068(100)$ & $235(22.0)$ & $833(78.0)$ \\
\hline Different Clinical Cases & & & \\
Severe & $321(30.0)$ & $119(37.1)$ & $202(62.9)$ \\
Moderate & $426(40.0)$ & $77(18.1)$ & $349(82.0)$ \\
Mild & $321(30.0)$ & $39(12.1)$ & $282(87.8)$ \\
\hline Total & $1068(100)$ & $235(22.0)$ & $\mathbf{8 3 3 ( 7 8 . 0 )}$ \\
\hline
\end{tabular}


Among total rotavirus infected children, male children $\quad(22.9 \%)$ were more infected than female children $(20.6 \%)$.

Table 3: Gender wise distribution of Rotavirus infection among study population

\begin{tabular}{lcccc}
\hline \multirow{2}{*}{ Gender } & Total N (\%) & Rotavirus & Negative & \multirow{2}{*}{ P-Value } \\
\cline { 3 - 4 } & & $\mathbf{N}(\%)$ & $\mathbf{N}(\%)$ & \\
\hline Male & $669(62.6)$ & $153(22.9)$ & $516(77.1)$ & $>0.05$ \\
Female & $399(37.4)$ & $82(20.6)$ & $317(79.4)$ & \\
\hline Total & $1068(100)$ & $235(22.0)$ & $833(78.0)$ & \\
\hline
\end{tabular}

According to age of children, rotavirus infection was found $\quad$ to be highest in 2 years and under 2 yearschildren (23.8\%).

Table 4: Age wise distribution of Rotavirus among study population.

\begin{tabular}{lccc}
\hline $\begin{array}{l}\text { Age groups in } \\
\text { years }\end{array}$ & $\begin{array}{c}\text { Total enrolled cases } \\
\mathbf{N}(\%)\end{array}$ & $\begin{array}{c}\text { Rotavirus } \\
\mathbf{N}(\%)\end{array}$ & $\begin{array}{c}\text { Negative } \\
\mathbf{N}(\%)\end{array}$ \\
\hline$\leq 2$ & $835(78.3)$ & $199(23.8)$ & $636(76.2)$ \\
$3-4$ & $149(13.9)$ & $26(17.4)$ & $123(82.6)$ \\
$5-6$ & $40(3.8)$ & $6(15.0)$ & $34(85.0)$ \\
$7-8$ & $23(2.1)$ & $3(13.0)$ & $20(87.0)$ \\
$9-10$ & $21(2.0)$ & $1(4.7)$ & $20(95.2)$ \\
\hline Total & $1068(100)$ & $235(22.0)$ & $833(78.0)$ \\
\hline
\end{tabular}

Among all season, the rotavirus infection was highest

$(26.7 \%)$ and others.

in winter seasons $(29.6 \%)$ followed by spring season

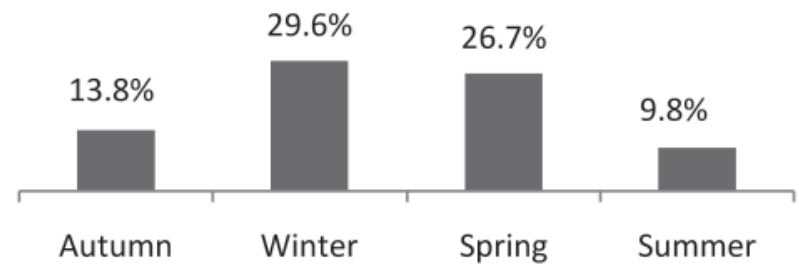

Figure 1: Season wise distribution of Rotavirus infection among study population

Among study population, the prevalence of rotavirus was found to be high in children with fathers having occupation labor $(27.8 \%)$ and found to be higher in children with illiterate mother $(38.9 \%)$.

Table 5: Characteristics of family background and Rotavirus among study population

\begin{tabular}{lcc}
\hline Father's occupation & Rotavirus N (\%) & Total N (\%) \\
\hline Business & $29(19.6)$ & $148(13.9)$ \\
Service & $49(25.9)$ & $189(17.7)$ \\
Agriculture & $57(20.8)$ & $274(25.7)$ \\
Labor & $55(27.8)$ & $198(18.5)$ \\
Driving & $38(18.9)$ & $201(18.8)$ \\
Other & $7(12.1)$ & $58(5.4)$ \\
\hline Total & $235(22.0)$ & $1068(100)$ \\
\hline Mother's education & & \\
None & $91(38.9)$ & $267(25.0)$ \\
primary & $58(19.7)$ & $364(34.1)$ \\
Secondary & $49(18.9)$ & $258(24.2)$ \\
Higher level & $37(20.1)$ & $179(16.8)$ \\
\hline Total & $235(22.0)$ & $1068(100)$ \\
\hline
\end{tabular}




\section{DISCUSSION}

As in other developing countries, diarrhoeal diseases are one of the primary health problems in Nepal. Rotavirus was one of leading diarrhoeal causing agent which was $22.0 \%$ positive from this study. This finding is in harmony with the study carried out by Saravanan (2004) in Chennai, South India in which the overall infection rate was to be $22.6 \%$ among children with acutediarrhoea.But some studies (Meqdam et al. 1997; Youssef et al. 2000 ; Rerksuppaphol et al. 2011) showed $33 \%$ to $40 \%$ of Rotavirus causing diarrhoea.

Rotavirus was higher in inpatient which was 196 (26.2\%) than in outpatients which was $36(11.2 \%)$ and the result was significant statistically $(\mathrm{P}<0.05)$. The proportion of rotavirus positive cases was always higher among hospitalized children than non-hospitalized children with acute gastroenteritis (Michiyo et al. 2004). From previous report, Rotavirus infection was found in 30.0$50.0 \%$ with acute gastroenteritis from hospitalized and none hospitalized infants and young children (Shariff et al. 2004; Sherchand et al. 2009). These all findings concur with this finding.

In this study, the clinical features of patients in relation to the microorganisms were isolated by a physician as having diarrhoea. Diarrhoea may be accompanied by cramping, abdominal pain, bloating, nausea, or an urgent need to use the bathroom. Among inpatient, 816 cases showed symptoms in which 663 cases has symptoms like nausea, vomiting, diarrhoea and fever whereas, 153 cases has other medical condition like pneumonia, enteric fever, typhoid etc. other medical condition children infected with Rotavirus is the important cause of hospital acquired infection (Chandran et al. 2006), Rotavirus were highest positive in systemic cases $24.4 \%(199 / 816)$. Though the result was significant statistically $(\mathrm{P}<0.05)$. On basis of patient's condition and physician reports, patients were categorized into three groups i.e. severe, moderate and mild. Most of the cases were moderate 426 (40.0\%) followed severe $321(30.0 \%)$ and mild 321(30.0\%) in which highest Rotavirus seen in severe case (37.1\%) with intravenous fluid treatment. Rotavirus is the most common cause of severe diarrhoea among infants and young children.

The diarrhoeal disease treatment include zinc supplementation, oral rehydration solution (ORS), antibiotic, IV etc. Rotavirus doesn't respond to antibiotic. ORS are only effective in the treatment of dehydration caused by Rotavirus but donot kill it. There are no antiviral agents available for the treatment of Rotavirus infection in Nepal.

The gender wise distribution of Rotavirus infection was found to be higher in male patients (22.9\%) which was found statistically insignificant. At similar result was also found by Rerksuppaphol and Rerksuppaphol (2011) in which male were higher in proportion (68.6\%) with Rotavirus. The study carried out in Nigeria also found the higher prevalence of $57.1 \%$ in male (Tinuade 2006). However, no association of rotavirus infection could be discerned between male $(23.9 \%)$ and female $(21.1 \%)$ children in a study carried out by Saravanan (2011).

According to the distribution of diarrhoea cases among the different age groups showed that the children less than 2 years $(78.3 \%)$ were more infected than other age groups which was $23.8 \%$ i.e. 199 out of 835 . Most of infected children in this study were under 2 years of age, with highest prevalence between 6 and 12 months. The greater risks of infants and young children in the period between 6 to 12 months with declined levels of maternal antibodies to rotavirus infection have been documented (Mata 1983 and Zheng 1992).

Under 2 years children, according to type of nutrition (breast feeding vs. bottle feeding) rotavirus found to be highest in breast feeding children than bottle feeding children. This may be due to the apparent lack of protection against rotavirus infection in this age group may be partly due to reduced total daily intake of breast milk or to the reduced amount of rotavirus antibody in mature breast milk or to both. However, study in Pakistan found that bottle feeding infants were about two folds higher rotavirus positive than in breast feeding infants which is not consistent with this finding. This may be different in sample sizes and types of nutrition intake along with breast milk (Kazemi 2001). Observations in studies suggested that active immunization through repeated exposure and prolonged breastfeeding may protect against the diarrhoeagenic effect of these agents (WHO 2009).

The highest positive cases of Rotavirus was observed in winter season constitute $29.6 \%$ followed by spring season $26.7 \%$, autumn season $13.8 \%$ and summer season $9.8 \%$. Similarly, Study conducted in Pakistan showed highest Rotavirus (41.4\%) in winter with 
highest prevalence in January (63.6\%) (Kazemi 2001). The result was consistent with the finding of Sherchand et al. (2004) in which Rotavirus was predominant in winter particularly in December to February. In contrast a study by Naficy et al. (1999) found that $90 \%$ of Rotavirus diarrhoeal episodes occurred between July and November. Saudi Arabia reported a peak for Rotavirus isolate during dry, hot season (Al-Bwardy et al. 1988). Rotavirus is a disease of later warm and early cool season but seasonally may vary year to year.

The diarrhoeal disease also related with socio economic status of family. So, in this study occupation of father was also mentioned. The rotavirus was found to be high in children with fathers having occupation labor $(27.8 \%)$. Due to low income in labour family, children may not get sufficient food, hygienic condition, treatment etc. The prevalence of rotavirus (38.9\%) found to be higher in children with illiterate mother. This may suggests that it was the better hygiene knowledge and practice of literate mothers that reduces the risk of childhood diarrhoea than illiterate mother. Literate mothers were more likely to seek medical care for a child with diarrhoea.

\section{CONCLUSION}

The incidence of diarrhoea has been drastically decreased due to improved sanitation and drinking water. However, winter diarrhoea did not reduce significantly, which could be attributed to Rotavirus infection. The routine diagnosis of Rotavirus in Nepal is not done. So it can be concluded that routine stool examination should include detection of Rotavirus antigen in diagnosis of acute pediatrics diarrhoeal illness which helps in manangement for diarrhoeal population.

\section{ACKNOWLEDGEMENTS}

The authors are grateful to Public Health Research Laboratory, Tribhuvan University Teaching Hospital (TUTH) for providing me a platform to work this research. We are also grateful to working staffs, doctors and Nursing Incharge of Kanti Children's Hospital, Maharajgunj, Kathmandu.

\section{REFERENCES}

Al-Bwardy MA, Ramia S, Al-Frayh AR et al. (1988) Bacterial, parasitic and viral enteropathogens associated with diarrhoea in Saudi children. Ann Trop Paediatr 8(1): 26-33.

Bishop RF (1996) Natural history of human Rotavirus infection. Arch Virol 12: 119-128.

Black RE, Nelson KE, Williams CM et al. (2001) Diarrhoeal diseases. Infect Dis Epidemiol 17: 497517.

Chandran A, Heinzen RR, Santosham M et al. (2006) Nosocomial Rotavirus infections: asystematic review. J Pediatr 149: 441-447.

Desselberger U, Mrukowicz J, Rodrigo C et al. (2006) Rotavirus types in Europe and their significance for vaccination. Pediatr infect Dis 25: 30- 41.

Estes MK (2001) Rotaviruses and their replication. Fields virology $5^{\text {th }}$ ed. Philadelphia; Lippincott Williams \& Wilkins pp: 1747-1785.

Kazemi FT, Agha-Ghazvini MR and Kelishadi R (2001) The Role of Rotavirus in acute pediatric diarrhoea in Isfahan, Iran. Pakistan J Med Sci 22: 282-285.

Mata L, Simhon A, Urruta JJ et al. (1983) Epidemiology of Rotaviruses in a cohort of 45 Guatamalan Mayan Indian children observed from birth to the age of three years. J Infect Dis 148(3): 452-461.

Meqdam MMM, Youssef MT, Nimri LF et al. (1997) Viral gastroenteritis among young children in Northern Jordan. J Trop Pediatr 43: 349-352.

Michiyo Y, Kokichi A, Osamu N et al. (2004) Estimation of annual incidence, age-specific incidence rate and cumulative risk of Rotavirus gastroenteritis among children in Japan. Jpn J Infect Dis 57: 166-171.

Naficy AB, Abu-Elyazeed R, Holmes JL et al. (1999) Epidemiology of Rotavirus diarrhoea in Egyptian children and implications for disease control. Am J Epidemiol 150(7): 770-777.

Nepal Population Report (NPR) (2007) Government of Nepal, ministry of health and population, population division, Kathmandu, Nepal pp: 77-100.

Pun SB, Nakagomi T, Sherchand JB et al. (2007) Detection of G12 human Rotaviruses in Nepal. Emerg Infect Dis 13: 482-484.

RerksuppapholSand Rerksuppaphol L (2011) Prevalence and clinical manifestations of Rotavirus diarrhoea in children of rural area of Thailand. Int J Collab Res Intern Med Public Health 3: 695-702.

Saravanan P, Ananthan S, Ananthasubramanian M (2004) Rotavirus infection among infants and 
young children in Chennai, South India. Indian J Med Microbiol 22(4) : 212-221.

Shariff M, Deb M and Singh R (2004) A study of diarrhoea among children in eastern Nepal with special reference to Rotavirus. Indian J Med Microbiol 21(2): 87-90.

Sherchand JB, Haruki K and Pandey BS (2004) Rotavirus study among children and animals of rural and urban communities of Nepal. J Nepal Health Res Council 2: 715-718.

Sherchand JB, Nakagomi O, Dove W et al. (2009) Molecular epidemiology of Rotavirus diarrhoea among children aged less-than 5 years in Nepal: Predominance of emergent G12 strains during 2 years. J Insect Dis 200: 182-187.

Sherchand JB, Ohara H, Sherpa K et al. (2011) Rotavirus nosocomial infection in children under 5 years of age: A preliminary study in Nepal. J Paediatr Soc 31: 30-34.

Tinuade O, John O and Saheed O (2006) Parasitic etiology of childhood diarrhoea. Indian J Pediatr 73(14): 1081-1084.
Uchida R, Pandey BD, Sherchand JB et al. (2006) Molecular epidemiology of Rotavirus diarrhoea among children and adults in Nepal: Detection of G12 strains with P [6] or P[8] and a G11P[25] strain. J Clin Microbiol 44: 3499-3505.

UNICEF/World Health Organization (2009) Diarrhoea, why children are still dying and what can be done. http://apps.who.int/iris/ bitstream/10665/44174/1/9789241598415_eng. pdf.

Velazquez FR, Matson DO, Calva JJ et al. (1996) Rotavirus infections in infants as protection against subsequent infections. N Engl J Med 335: 1022-1028.

Youssef M, Shurman A, Bougnoux M et al. (2000). Bacterial, viral and parasitic enteric pathogens associated with acute diarrhoea in hospitalized children from northern Jordan. FEMS Immunol Med Microbiol 28: 257-263.

Zheng BJ, Ma GZ, Tam JSL et al. (1992) The effects of maternal antibodies on neonatal Rotavirus infection. Pediatr Infect Dis 10: 865-868. 